\title{
The Effects of Early Feed Restriction on Growth Performance, Internal Organs and Blood Biochemical Indicators of Broilers
}

\author{
Chenxi Xu ${ }^{1}$, Haiming Yang ${ }^{1, *}$, Zhiyue Wang ${ }^{1}$, Yan Wan ${ }^{2}$, Banghong Hou ${ }^{2}$, Chuan Ling ${ }^{2}$ \\ ${ }^{1}$ College of Animal Science and Technology, Yangzhou University, Yangzhou, P. R. China \\ ${ }^{2}$ Jiangsu Dadi Animal Health Products co., LTD, Huaian, P. R. China
}

\section{Email address:}

yhmdlp@qq.com (Haiming Yang)

${ }^{*}$ Corresponding author

\section{To cite this article:}

Chenxi Xu, Haiming Yang, Zhiyue Wang, Yan Wan, Banghong Hou, Chuan Ling. The Effects of Early Feed Restriction on Growth Performance, Internal Organs and Blood Biochemical Indicators of Broilers. Animal and Veterinary Sciences. Vol. 5, No. 6, 2017, pp. 121-125. doi: $10.11648 /$ j.avs.20170506.14

Received: September 30, 2017; Accepted: October 23, 2017; Published: December 8, 2017

\begin{abstract}
The growth rate of broiler chickens has increased greatly due to enhancement in genetics, nutrition and management. However, the high growth rate of broilers has caused many health problems, To avoid those problems, feed restriction was used as a management strategy to prevent excessive growth during early period. This study accessed the effects of early feed restricted on growth performance, internal organs and blood biochemical indicators of broilers. A total of 180 male Arbor Acres broilers were obtained and randomly assigned to 2 treatment groups. The treatments included control group (basal diet and feed restricted group (dietary energy and protein levels were diluted by $10 \%$ ). At $14 \mathrm{~d}$, two birds of each replicate were randomly chosen, wing vein blood samples were taken for blood biochemical indicators determination, then slaughtered to measure internal organs. The result showed that birds fed diluted feed had lower $(P<0.05)$ body weight at 14 days. There was no significant difference in body weight between restricted and control groups at 42 days. No changes were observed in feed intake and feed conversion ratio between groups. Feed restriction also had no significant effects on internal organs, intestine and serum biochemical indicators. Taken together, this study suggested that dietary protein and energy diluted by $10 \%$ from 8 to $14 \mathrm{~d}$ is a suitable feeding program.
\end{abstract}

Keywords: Early Feed Restriction, Broilers, Growth Performance

\section{Introduction}

Constant improvement in genetic selection and nutrition has led to a rapid growth rate of modern broilers. These advances have brought better production indexes, but on the other hand, many unexpected results occurred which included body fat deposition, high mortality and high incidence of metabolic disorders and bone diseases [1]. Thus feed restriction in broilers was used as a management strategy to prevent excessive growth during early period and thereby to solve those health issues. Previous studies have found that feed restriction could reduce considerably the incidence of ascites syndrome, sudden death syndrome and legs disease and other metabolic disease in broilers, but also can reduce abdominal fat deposition ([2], [3], [4]).

Limiting feed is artificially reducing the nutritional intake of chickens from quantity or quality, which will restrain or even suspend the growth of animal body, so that the body grew with a slow growth speed. A large number of studies have shown that early quantitative feed restriction of broilers could improve the feed conversion ratio with no adverse effects on growth performance ([5], [6]). In addition, quantity or timing feed restriction was demonstrated to be suitable as management means to slow down the speed of initial growth under the premise of not damaging the final performance of male and female Cobb broilers [7]. But, some scholars suggested that quantitative feed restriction may also result in a reduction in other aspects of welfare, thus the development of alternative solutions and modifying the current feed restriction plan is the key to improve the welfare of broiler [8]. Extensive experiments based on dietary nutrition dilution in broilers were conducted. Dietary energy restricted by $30 \%$ could caused a 
significant increment in the body weight gain and feed conversation ratio of broilers at later period, and decreased abdominal fat deposition [9]. However, there are few researches about restricting energy and protein simultaneously have been covered. This study, therefore, carried out to evaluate the effect of early feed restriction programs via decreasing the level of energy and protein by $10 \%$ on growth performance, internal organs and blood biochemical indicators of broilers.

\section{Materials and Methods}

\subsection{Experiment Design and Diet}

Our trial was conducted in the experimental base of the Yangzhou institute of poultry science, in Yizheng city, China. In this study, 180 AA male broilers were obtained and randomly allocated into 2 treatments with 6 replicates in each treatment and per replicate consisted of 15 birds. Treatments were applied from 8 to $14 \mathrm{~d}$ as follows: control group (T1: without feed restriction); feed restricted group (T2: energy and protein levels were diluted by $10 \%$ ). Feed and water were free for all chicks during the whole trial period.

This experiment included two stages of 1-21 day (starter) and 22-42 day (grower), basal diets were formulated to meet the nutrient demand for chickens. The composition and nutrition level of the test diets are shown in Table 1.

Table 1. Ingredients and nutrient levels of experimental diet.

\begin{tabular}{|c|c|c|c|c|}
\hline Ingredients, $\%$ & $\begin{array}{l}\text { T1 } \\
\text { (8-14d) }\end{array}$ & $\begin{array}{l}\text { T2 } \\
(8-14 d)\end{array}$ & $\begin{array}{l}1-7 d, \\
15-21 d\end{array}$ & 22-42d \\
\hline Corn & 57.13 & 55.50 & 57.13 & 62.20 \\
\hline All soybean meal & 32.54 & 28.23 & 32.54 & 28.30 \\
\hline Corn protein meal & 3.45 & 1.10 & 3.45 & 2.00 \\
\hline Soybean oil & 2.40 & 0.46 & 2.40 & 3.52 \\
\hline Wheat bran & 0.10 & 10.24 & 0.01 & 0.00 \\
\hline Limestone & 1.25 & 1.25 & 1.25 & 1.25 \\
\hline Calcium hydrogen phosphate & 2.00 & 2.00 & 2.00 & 1.65 \\
\hline DL-Met & 0.17 & 0.17 & 0.17 & 0.10 \\
\hline 98\% Lys & 0.08 & 0.08 & 0.08 & 0.08 \\
\hline $\mathrm{NaCl}$ & 0.35 & 0.35 & 0.35 & 0.35 \\
\hline $50 \%$ Choline chloride & 0.26 & 0.26 & 0.26 & 0.20 \\
\hline Aureomycin & 0.10 & 0.10 & 0.10 & 0.10 \\
\hline Antioxidant & 0.03 & 0.03 & 0.03 & 0.03 \\
\hline Microelement $^{\circ}$ & 0.20 & 0.20 & 0.20 & 0.20 \\
\hline Vitamine\# & 0.03 & 0.03 & 0.03 & 0.02 \\
\hline Tatol & 100 & 100 & 100 & 100 \\
\hline \multicolumn{5}{|l|}{ Nutrient levels, $\mathrm{MJ} / \mathrm{kg}$} \\
\hline Metabolic energy & 2952 & 2681 & 2952 & 3051 \\
\hline Crude protein & 21.51 & 19.45 & 21.51 & 19.00 \\
\hline Crude fiber & 2.89 & 4.47 & 2.89 & 2.74 \\
\hline Lys & 1.11 & 1.02 & 1.11 & 1.00 \\
\hline Met & 0.50 & 0.46 & 0.50 & 0.39 \\
\hline $\mathrm{Ca}$ & 1.16 & 1.17 & 1.16 & 1.04 \\
\hline Total phosphorus & 0.83 & 0.84 & 0.83 & 0.73 \\
\hline Non-phytate phosphorus & 0.59 & 0.59 & 0.59 & 0.51 \\
\hline
\end{tabular}

Met, methionine; Lys, lysine; ME, metabolizable energy; $\mathrm{CP}$, crude protein; nPP, non-phytate phosphorus; TP, total phosphorus; $\mathrm{Ca}$, calcium. Values are expressed on air-dry basis. The microelement provided per kilogram of diet: iron,
$80 \mathrm{mg}$; copper, $8 \mathrm{mg}$; manganese, $100 \mathrm{mg}$; zinc, $80 \mathrm{mg}$; iodine, $0.70 \mathrm{mg}$; selenium, $0.30 \mathrm{mg}$. \#The vitamine provided per kilogram of diet: vitamin A, $8000 \mathrm{U}$; vitamin D3, 1000U; vitamin $\mathrm{E}, 20 \mathrm{U}$; vitamin $\mathrm{K} 3,0.5 \mathrm{mg}$; vitamin $\mathrm{B} 1,2 \mathrm{mg}$; vitamin B2, $8 \mathrm{mg}$; vitamin B6, $3.5 \mathrm{mg}$; vitamin B12, $10 \mu \mathrm{g}$; nicotinic acid, $35 \mathrm{mg}$; calcium pantothenate, $10 \mathrm{mg}$; folic acid, $0.55 \mathrm{mg}$; biotin, $0.18 \mathrm{mg}$.

\subsection{Sample Collection and Analytical Determination}

At 7, 14 and $42 \mathrm{~d}$, individual body weights were measured to determine body weight $(\mathrm{BW})$, average daily feed intake (ADFI), and feed conversion ratio (FCR). At 14 days old, two birds were randomly selected from each replicate of each treatment, and $2.5 \mathrm{ml}$ of blood was collected from the wing vein for blood clinical chemistry. Then the birds were dissected and internal organs weight were measured.

Animal care use and protocols were approved by the Yangzhou University Animal Care and Use Committee.

\subsection{Feeding and Management}

During the experiment, the daily illumination and immunization program is carried out in accordance with the routine management of broiler. The temperature of the room was maintained at 30 to $32^{\circ} \mathrm{C}$ at the first week and then was reduced to $2^{\circ} \mathrm{C}$ every week until the house temperature was $25^{\circ} \mathrm{C}$. Lighting via incandescent lighting and hours of light was $24 \mathrm{~h}$ in the first four days, the next $5 \mathrm{~d}$ of $20 \mathrm{~h}$ of light, $10-15 \mathrm{~d}$ of $18 \mathrm{~h}$ of light, and $16 \mathrm{~h}$ of light for the remained of the experiment. Utilized natural light to illuminate during the day time and used incandescent to prolong lighting time in the night. The birds were housed in the main compartment, in floor pens fitted with electrical heaters. Humidity was maintained at least at 55 to $65 \%$ in the early growing period.

\subsection{Statistical Analyses}

Data gathered during the trials were organized in Excel data sheets and the statistical analyses were performed with SPSS version 17.0 software. Significant differences among treatment means were determined at $P<0.05$ by Independent-Samples $\mathrm{T}$ Test. Results were given in mean \pm standard error of mean $(\overline{\mathrm{x}} \pm \mathrm{SEM})$.

\section{Result}

\subsection{Growth Performance}

From 8 to $14 \mathrm{~d}$, body weight of the restricted birds was lower than that in control group (Table 2). Significant different in body weight was observed at 14 days $(P=0.01)$, the restricted group was significantly lower than that of the control group. There was no significant difference in ADFI and FCR $(P>0.05)$.

At 42 days, body weight of feed restriction group was higher than that of control group (Table 3), ADFI and FCR of feed restriction group were lower compared to the control group, but the data both showed no significance $(P>0.05)$. 
Table 2. Effects of early feed restriction on growth performance in broilers from 8 to 14 days.

\begin{tabular}{lllll}
\hline Items & BW of $7 \mathbf{~ d ~}(\mathbf{g})$ & BW of $\mathbf{1 4} \mathbf{~ d ~}(\mathbf{g})$ & ADFI $(\mathbf{g})$ & FCR \\
\hline T1 & $180.63 \pm 0.41$ & $472.48 \pm 5.62^{\mathrm{a}}$ & $56.99 \pm 1.13$ & $1.38 \pm 0.04$ \\
T2 & $180.53 \pm 3.83$ & $448.26 \pm 5.23^{\mathrm{b}}$ & $56.38 \pm 0.33$ & $1.44 \pm 0.03$ \\
$P$-value & 0.862 & 0.010 & 0.612 & 0.228 \\
\hline
\end{tabular}

BW, body weight; ADFI, average daily feed intake; FCR, feed conversion ratio.

${ }^{a-b}$ Values within a column with no common superscript differ significantly $(\mathrm{P}<0.05)$.

Table 3. Effects of early feed restriction on growth performance in broilers at 42 days.

\begin{tabular}{llll}
\hline Items & BW of $\mathbf{4 2} \mathbf{~ d ~}(\mathbf{g})$ & ADFI $(\mathbf{g})$ & FCR \\
\hline T1 & $2821.07 \pm 72.15$ & $155.42 \pm 1.92$ & $1.70 \pm 0.06$ \\
T2 & $2856.78 \pm 21.67$ & $152.90 \pm 0.42$ & $1.65 \pm 0.01$ \\
$P$-value & 0.646 & 0.229 & 0.345 \\
\hline
\end{tabular}

$\mathrm{BW}$, body weight; ADFI, average daily feed intake; FCR, feed conversion ratio.

${ }^{\mathrm{a}-\mathrm{b}}$ Values within a column with no common superscript differ significantly $(\mathrm{P}<0.05)$.

\subsection{Growth of Internal Organs}

The effects of early feed restriction on growth of internal organs of broilers from 8 to $14 \mathrm{~d}$ are summarized in Table 3 . No significant effects were observed on the index of heart, liver, spleen, proventriculus and gizzard between two groups $(P>0.05)$.

Table 4. Effects of early feed restriction on internal organ index in broilers from 8 to 14 days.

\begin{tabular}{llllll}
\hline Items & Heart index & Liver index & Spleen index & Proventriculus index & Gizzard index \\
\hline T1 & $0.71 \pm 0.02$ & $2.80 \pm 0.06$ & $0.08 \pm 0.01$ & $0.69 \pm 0.02$ & $2.37 \pm 0.08$ \\
T2 & $0.70 \pm 0.03$ & $2.79 \pm 0.06$ & $0.08 \pm 0.01$ & $0.70 \pm 0.02$ & $2.43 \pm 0.06$ \\
$P$-value & 0.726 & 0.950 & 0.568 & 0.881 & 0.500 \\
\hline
\end{tabular}

\subsection{Growth of Small Intestine}

The effects of early feed restriction on growth of small intestine of broilers from 8 to $14 \mathrm{~d}$ are showed in Table 4 . There were no significant difference in small intestine weight and length at $14 \mathrm{~d}$ between the broilers of two dietary treatments $(P>0.05)$.

Table 5. Effects of early restriction on growth of small intestine in broilers from 8 to 14 days.

\begin{tabular}{|c|c|c|c|c|c|c|c|c|c|}
\hline Item & $\begin{array}{l}\text { Duodenum } \\
\text { weight (g) }\end{array}$ & $\begin{array}{l}\text { Jejunum } \\
\text { weight (g) }\end{array}$ & $\begin{array}{l}\text { Ileum } \\
\text { weight (g) }\end{array}$ & $\begin{array}{l}\text { Caecum } \\
\text { weight (g) }\end{array}$ & $\begin{array}{l}\text { Rectum } \\
\text { weight (g) }\end{array}$ & $\begin{array}{l}\text { Duodenum } \\
\text { length }(\mathrm{cm})\end{array}$ & $\begin{array}{l}\text { Jejunum } \\
\text { length }(\mathrm{cm})\end{array}$ & $\begin{array}{l}\text { Ileum } \\
\text { length }(\mathrm{cm})\end{array}$ & $\begin{array}{l}\text { Caecum } \\
\text { length }(\mathrm{cm})\end{array}$ \\
\hline $\mathrm{T} 1$ & $4.16 \pm 0.18$ & $7.81 \pm 0.23$ & $5.93 \pm 0.23$ & $2.25 \pm 0.12$ & $1.18 \pm 0.07$ & $18.15 \pm 0.58$ & $45.3 \pm 1.06$ & $50.38 \pm 1.18$ & $9.88 \pm 0.26$ \\
\hline $\mathrm{T} 2$ & $4.01 \pm 0.17$ & $7.88 \pm 0.21$ & $5.78 \pm 0.16$ & $2.18 \pm 0.09$ & $1.14 \pm 0.07$ & $18.67 \pm 0.44$ & $49.31 \pm 2.55$ & $49.31 \pm 1.47$ & $9.91 \pm 0.28$ \\
\hline$P$-value & 0.553 & 0.829 & 0.595 & 0.654 & 0.741 & 0.483 & 0.797 & 0.576 & 0.948 \\
\hline
\end{tabular}

\subsection{Serum Biochemical Indicators}

The effects of early feed restriction on serum biochemical indicators of broilers from 8 to $14 \mathrm{~d}$ are showed in Table 5. Dietary treatments were observed to have no significant effects on TP, ALB, GLB, A/G and ALP levels in serum of broilers at $14 \mathrm{~d}(P>0.05)$.

Table 6. Effects of early restriction on serum biochemical indicators in broilers from 8 to 14 days.

\begin{tabular}{llllll}
\hline Item & TP $(\mathbf{g} / \mathbf{L})$ & $\mathbf{A L B}(\mathbf{g} / \mathbf{L})$ & $\mathbf{G L B}(\mathbf{g} / \mathbf{L})$ & $\mathbf{A} / \mathbf{G}$ & $\mathbf{A L P}(\mathbf{U} / \mathbf{L})$ \\
\hline T1 & $22.97 \pm 0.85$ & $8.81 \pm 0.33$ & $14.16 \pm 0.53$ & $0.62 \pm 0.01$ & $6220.25 \pm 554.39$ \\
T2 & $24.17 \pm 0.52$ & $9.30 \pm 0.21$ & $14.87 \pm 0.35$ & $0.63 \pm 0.01$ & $5529.67 \pm 668.71$ \\
$P$-value & 0.240 & 0.222 & 0.271 & 0.837 & 0.435 \\
\hline
\end{tabular}

\section{Discussion}

\subsection{Growth performance}

Our results indicated that the BW of birds in the feed restricted group decreased significantly compared to control group at $14 \mathrm{~d}$, this result showed that tested chicks could not get enough nutrition to achieve the normal weight when dietary energy and protein were reduced. This finding was consistent with Teimouri [10], who found that different level of dietary dilution from 8 to 14 days could affect body weight of broilers, with increasing dilution rate the weight gain of broilers was significantly decreased compared with control group. Some reports also indicated that energy and protein dilution on broiler chickens can decreased growth rate of broilers ([11], [12]). A result showed that nutrient density decreased by $28 \%$ has caused a significant reduction in body weight gain and live weight at 45d [13], Urdanetarincon and Leeson conducted a experiment with different feed restriction 
types and levels to evaluate that the effect of diets dilution on the performance of male broilers, results from qualitative feed restriction treatment stated that body weight has a significant difference between control group and restricted group [3].

In our study, there was no significant difference in body weight between unrestricted and restricted chicks at 42 days. Broilers could show compensatory growth after feed restriction. This is in agreements with the findings of Tumova et al.; Lee and Leeson ([14], [15]).

The data of our study showed that ADFI of restricted group was lower than that of control group, but the difference were not significant. At present, there are many related experiments showed that feed restriction can affect the daily feed intake of broilers, but the results are different. Sharma [12] reported that feed intake was reduced significantly in whole grain added diets, this finding supported the findings of Shi et al. [16]. These results are contrary to those of others researches ([11], [17]). They considered that it is possible to increased feed intake because of broiler chicks try their best to absorb more feed while in low dietary energy, so as to satisfy the demand of the high growth rate. In general, early dietary energy and protein dilution have significant effect on growth performance.

\subsection{Growth of Internal Organ}

Statistical analysis showed that early feed restriction had no significant effects on the relative weight of internal organ of broilers ([18], [19]). Similar founding was also observed in the present experiment. On the other hand, chicks preferentially developed their supply organs such as the stomach when the feed was diluted [12]. Onbaşılar mentioned that there were no significant association on other examined organs except heart among groups [20]. Accordingly, the reason for no significant difference on internal organs in present study could be the degree of dilution and diluted material were varied.

\subsection{Growth of Small Intestine}

At present, there are few researches about the effect of restricted feeding on the growth and development of small intestine in broilers. In this experiment, no significant differences were found in small intestine weight and length between the broilers of two treatments, this results were consistent with previous studies. Wijtten carried out a study to investigated the effect of dietary feed restriction in early life, then they observed that energy dilution had no effect on the weight and length of small intestine [21], Similar results were found in other studies [22]. As the case stands, it is not clear about the mechanisms of limited feeding on growth of small intestine and further studies are needed.

\subsection{Blood Biochemical Indicators}

Blood metabolites reflect the immediate nutritional status of birds. By decreasing dietary energy may lead to dramatic changes to the plasma biochemistry. In the presented study, there are no significant effects on the blood contents of total protein, albumin, globulin, and alkaline phosphatase of chicks.
These results are support to those of Azis et al. [23]. Previous studies in poultry have indicated that dietary dilution can improved the plasma levels of hormones. Data gathered in a study conducted by Jahanpour showed that quantitative feed restriction was related to changes in plasma metabolite concentrations [24]. The results of this study are supported by Rajman et al. [25], who reported that quantitative feed restriction significantly decreased $\mathrm{TG}$ in broiler breeder chickens at 58 and $100 \mathrm{~d}$.

\section{Conclusion}

This study suggested that dietary protein and energy reduced $10 \%$ from 8 to $14 \mathrm{~d}$ of age could improved bird growth, and have no side influence on other indexes in broilers. It proved that dietary protein and energy reduced $10 \%$ is a suitable feeding program, which can implied in the production of broilers.

\section{Acknowledgements}

This research was financially supported by the Priority Academic Program Development of Jiangsu Higher Education Institution and the Northern Jiangsu Special Project of Science and Technology of Jiangsu Province (NO. BN2015136), P. R. China.

\section{References}

[1] Zubair A K, Leeson S, 1996. Compensatory growth in the broiler chicken: a review. Worlds Poultry Science Journal. 52, 189-201.

[2] Acar N, Sizemore F G, Leach G R, et al., 1995. Growth of broiler chickens in response to feed restriction regimens to reduce ascites. Poultry Science. 74, 833-843.

[3] Urdanetarincon $M$ and Leeson S, 2002. Quantitative and qualitative feed restriction on growth characteristics of male broiler chickens. Poultry Science. 81, 679-688.

[4] Santoso U, 2002. Effects of early feed restriction on the occurrence of compensatory growth, feed conversion efficiency, leg abnormality and mortality in unsexed broiler chickens reared in cages. Asian-australasian journal of animal sciences. 15, 1319-1325.

[5] Deaton J W, 1995. The effect of early feed restriction on broiler performance. Poultry Science. 74, 1280-1286.

[6] Komprda T, Zelenka J, Fajmonová E, et al. 2000. Meat quality of broilers fattened deliberately slow by cereal mixtures to higher age:1. Growth and sensory quality. Archive Fur Geflugelkunde. 64, 167-174.

[7] Butzen F M, Ribeiro A M L, Vieira M M, et al. 2013. Early feed restriction in broilers. I-Performance, body fraction weights, and meat quality. The Journal of Applied Poultry Research. 22, 251-259.

[8] Mench J A, 2002. Broiler breeders: feed restriction and welfare. Worlds Poultry Science Journal, 58, 23-29. 
[9] Chen W, Guo Y M, Huang Y Q, et al., 2012. Effect of Energy Restriction on growth, slaughter performance, serum biochemical parameters and Lpin2/WDTC1/mRNA expression of broilers in the later phase. Journal of Poultry Science. 49, 12-19.

[10] Teimouri A, Rezaei M, Pourreza J, et al., 2006. Effect of diet dilution in the starter period on performance and carcass characteristics of broiler chicks. International Journal of Poultry Science. 7, 63-69.

[11] Rezaei M and Hajati H, 2010. Effect of diet dilution at early age on performance, carcass characteristics and blood parameters of broiler chicks. Italian Journal of Animal Science. 9, 93-100.

[12] Sharma N K, Sapkota M, Sah R, et al., 2013. Performance and Carcass Characteristics of Broilers Under Diets Supplemented with Whole Grains. Nepal Journal of Science and Technology. $13,21-28$

[13] Sahraei M and Shariatmadari F, 2007. Effect of different levels of diet dilution during finisher period on broiler chickens performance and carcass characteristics. International Journal of Poultry Science. 6, 280-282.

[14] Tumova E, M Skirvan, V Skirvanova, L Kacerovska, 2002. Effect of early feed restriction on growth in broiler chickens, turkeys and rabbits. Czech Journal of Animal Science Uzpi. 47, 418-428.

[15] Lee K H and Leeson S, 2001. Performance of broilers fed limited quantities of feed or nutrient during seven to fourteen $\mathrm{d}$ of age. Poultry Science. 80, 446-454.

[16] Shi B M, Shan A S, Chan L, 2005. Effects of Diet Dilution during the Finishing Period on the Performance and Carcass Characteristics of Broiler Chickens. Journal of Northeast Agricultural University (English Edition). 12, 122-125.

[17] Hassanabadi A, 2008. The Effects of Early Age Feed Restriction on Performance and Carcass Characteristics of Male Broiler Chickens. Journal of Animal and Veterinary Advances. 7, 372-376.
[18] Yang Y X, Guo J, Yoon S Y, et al., 2009. Early energy and protein reduction: effects on growth, blood profiles and expression of genes related to protein and fat metabolism in broilers. British Poultry Science. 50, 218-227.

[19] Fontana E A, Jr W W, Denbow, 1993. Early feed restriction of broilers: effects on abdominal fat pad, liver, and gizzard weights, fat deposition, and carcass composition. Poultry Science. 72, 243-250.

[20] E E Onbaşılar S. Yalçın E. Torlak et al., 2009. Effects of early feed restriction on live performance, carcass characteristics, meat and liver composition, some blood parameters, heterophil-lymphocyte ratio, antibody production and tonic immobility duration. Tropical Animal Health and Production. 41, 1513-1519.

[21] Wijtten P J A, Hangoor E, Sparla J K W M, et al., 2010. Dietary amino acid levels and feed restriction affect small intestinal development, mortality, and weight gain of male broilers. Poultry Science. 89, 1424-1439.

[22] Palo P E, Sell J L, Piquer F J, et al., 1995. Effect of Early Nutrient Restriction on Broiler Chickens.:1. Performance and Development of the Gastrointestinal Tract. Poultry Science. 74, 88-101.

[23] Azis A, Abbas H, Heryandi Y, et al.,2010. Thyroid hormone and blood metabolites concentrations of broiler chickens subjected to feeding time restriction. Media Peternakan. 35, 32-37.

[24] Jahanpour H, Seidavi A, Qotbi A A A, et al., 2015. Effects of the level and duration of feeding restriction on carcass components of broilers. Archive Fur Tierzucht. 58, 99-105.

[25] Rajman M, Juráni M, Lamosová D, et al., 2006. The effects of feed restriction on plasma biochemistry in growing meat type chickens (Gallus gallus). Comparative Biochemistry and Physiology Part A Molecular and Integrative Physiology. 145, 363-371. 